\title{
Effect of Multiple Micronutrient Fortification on Physico-Chemical and Sensory Properties of Chhash (Traditional Indian Yogurt-Based Drink)
}

\author{
Shashank Gaur ${ }^{1}$ (D), Anna W. Waller ${ }^{1}$ and Juan E. Andrade 1,2,*(D) \\ 1 Food Science and Human Nutrition, University of Illinois, Urbana-Champaign; Urbana, IL 61801, USA; \\ gaur2@illinois.edu (S.G.); awaller2@illinois.edu (A.W.W.) \\ 2 Division of Nutritional Sciences, University of Illinois, Urbana-Champaign; Urbana, IL 61801, USA \\ * Correspondence: jandrade@illinois.edu; Tel.: +1-217-333-9653
}

Received: 11 November 2018; Accepted: 21 December 2018; Published: 22 December 2018

\begin{abstract}
Introduction: Micronutrient malnutrition is a persistent problem in India mainly due to low dietary diversity and poor nutrient density of staple foods. The addition of a commercial micronutrient mix in terms of physico-chemical and sensory characteristics was evaluated. Methods: The yogurt prepared with reduce-fat milk (2\%), $20 \mathrm{~g} / \mathrm{L} \mathrm{CHN}-11$ fermentation culture and $12 \mathrm{~h}$ incubation $\left(42{ }^{\circ} \mathrm{C}\right)$ was diluted at a rate of $35 \%$ to yield a $32 \mathrm{mg} / 100 \mathrm{~mL}$ concentration. The premix provided vitamin $\mathrm{A}$, vitamin $\mathrm{D}$, folic acid, iodine, iron, and zinc oxide to cover $\sim 20-35 \%$ recommended RDA (recommended dietary allowance) per serving $(250 \mathrm{~mL})$. A three-factorial design, 2 treatments (control and fortified), 3 temperatures $\left(4,25\right.$, and $\left.40^{\circ} \mathrm{C}\right)$ and 4 time points $(1,2,3$ and 6 days), was used to analyze the physico-chemical properties in terms of titratable acidity, $\mathrm{pH}$, color, and viscosity. A discriminatory sensory test (triangle) was performed with college students $(n=58)$ and mothers with young children $(n=25)$, who were living in Mehsana, India to evaluate the difference between fortified and non-fortified cooled $\left(4{ }^{\circ} \mathrm{C}\right)$ product. Results: Fortification did not affect most of the physico-chemical properties of chhash. As expected, titratable acidity increased whereas $\mathrm{pH}$ decreased with increasing storage time and temperature. Fortified samples showed higher $b^{*}$ values, whereas $L^{*}$ and $a^{*}$ were not affected. Viscosity changed due to temperature and time, but not fortification. Participants could not discriminate between samples in terms of color, aroma, and taste. Conclusion: Fortification of chhash is technically feasible.
\end{abstract}

Keywords: fortification; malnutrition; micronutrient; fermented product

\section{Introduction}

Micronutrient malnutrition or the deficiency of essential vitamins and minerals afflicts close to 1.5 billion people worldwide, especially in India where a large proportion of the population lives in poverty and food insecurity [1]. Micronutrient deficiencies are associated with unacceptably high morbidity and mortality in children and pregnant women. More than $70 \%$ of Indian population consumes less than $50 \%$ recommended dietary allowance (RDA) of micronutrients, typically due to inadequate food intake, poor nutrient bioavailability (inhibitors, preparation method, interactions), and/or the presence of infections [2]. Vitamin A deficiency affects $57 \%$ of children under five and their mothers and results in the death of 333,000 children every year. Anemia results in a yearly loss of lives of 22,000 pregnant women. Every year, around 200,000 infants are born with neural tube defects as a result of folic acid deficiency [3]. Micronutrient malnutrition results in poor physical and mental development in children, losses in productivity among adults, and an increased vulnerability to infectious diseases [4]. 
The fortification of foods, especially of dairy products, is a well-established and successful practice in many high- and low-income countries, which contributes to effectively overcoming micronutrient deficiencies [5,6]. Although India is the largest producer of milk in the world, fortified dairy products are limited in Indian marketplaces. Nevertheless, in response to a newly implemented "Food Fortification Regulation," dairy products such as Vitamins A and D fortified milk are now emerging in the Indian markets. The Food Safety and Standards Authority of India (FSSAI) currently recommends fortification of milk with $270-450 \mu \mathrm{g}$ of Vitamin A (retinyl acetate or palmitate) and 5.0-7.5 $\mu \mathrm{g}$ of Vitamin D (cholecalciferol and ergocalciferol from plant sources) per liter of milk to provide $15-30 \%$ of the daily requirements [7].

Dairy products such as flavored milk, yogurt, and ice cream are examples of market-driven fortification vehicles, however, there is limited evidence on the fortification of other traditional products. Chhash is a traditional, low-cost, fermented dairy product in India. Chhash, also known as sour cultured buttermilk, contains $1 \%$ fat, $5.5 \%$ solids not fat (SNF) and minimum acidity of $0.8 \%$ lactic acid (equivalents). Chhash is widely consumed in India for its palatability, thirst-quenching characteristic and its potential therapeutic value based on its probiotic content $[8,9]$. The shelf life of a pasteurized chhash packaged in plastic pouches (polyethylene) is $48 \mathrm{~h}$ when stored below $8{ }^{\circ} \mathrm{C}$.

Fortification of dairy products with micronutrients is known to impact the physico-chemical and sensory properties of dairy products $[10,11]$. The objective of this study was to systematically evaluate the effect of chhash fortification on the physical-chemical and sensory characteristics stored at different temperature conditions.

\section{Materials and Methods}

\subsection{Materials}

Organic Horizon homogenized reduced-fat milk (2\%) was purchased at a local supermarket, Champaign, Illinois. Yogurt culture CHN-11 mesophilic aromatic was donated by CHR Hansen (Milwaukee, WI, USA). Fortitech yogurt micronutrient premix (Table 1) was donated by DSM, Gurgaon, India. Sodium hydroxide and Phenolphthalein indicator were procured from Sigma-Aldrich (St. Louis, MO, USA). Mason jars of $250 \mathrm{~mL}$ were procured from Ball (Broomfield, CO, USA).

Table 1. Composition of yogurt premix (per $32 \mathrm{mg}$ in $250 \mathrm{~mL}$ of product) and proportion of recommended dietary allowance.

\begin{tabular}{ccccc}
\hline Nutrient & Unit & Amount & RDA $^{\mathbf{1}}$ & \% RDA Covered $^{\mathbf{2}}$ \\
\hline Vitamin A (Retinol Acetate) & $\mu \mathrm{g}$ & 150 & $400 \mid 700$ & $37.5 \mid 21.4$ \\
Vitamin D2 (ergocalciferol) & $\mu \mathrm{g}$ & 3 & $15 \mid 15$ & $20 \mid 20$ \\
Folic Acid & $\mu \mathrm{g}$ & 27.8 & $200 \mid 400$ & $14.0 \mid 7.0$ \\
Iron (Ferric Pyrophosphate) & $\mathrm{mg}$ & 4.2 & $10 \mid 8$ & $42.0 \mid 52.5$ \\
Zinc (Zinc oxide) & $\mathrm{mg}$ & 2.33 & $5 \mid 11$ & $46.6 \mid 21.2$ \\
Iodine (Potassium Iodide) & $\mu \mathrm{g}$ & 22.5 & $90 \mid 150$ & $25 \mid 15$ \\
\hline
\end{tabular}

${ }^{1}$ From the USA Food and Nutrition Board, RDA for children (4-8 years) I men (19-70 years); ${ }^{2}$ Calculated as the amount of nutrient from 1 portion size $(250 \mathrm{~mL})$ divided by RDA for each age group; RAD, recommended dietary allowance.

\subsection{Design}

A three factorial-2 treatments (control and fortified), 3 temperatures $\left(4,23\right.$ and $\left.40{ }^{\circ} \mathrm{C}\right)$ and 4 time points (1, 2, 3 and 6 days) was utilized to analyze the effect of fortification on the physico-chemical properties of chhash.

\subsection{Culture Taxonomy}

The culture taxonomy of CHN-11 culture was Lactococcus lactis subsp. cremoris, Leuconostoc, Lactococcus lactis subsp. lactis, Lactococcus lactis subsp. lactis biovar diacetylactis. This culture was 
selected to match the culture generally used by the Indian dairy companies (Dudhsagar Dairy, Mehsana, GJ, India) for preparation of chhash.

\subsection{Chhash Preparation}

Chhash was prepared using a method adapted from Dudhsagar Dairy (Mehsana, GJ, India). Milk ( $1.5 \mathrm{~kg}, 2 \%$ fat, and $9 \% \mathrm{SNF}$ ) was heated on the stovetop to $42{ }^{\circ} \mathrm{C}$, measured using a handheld thermometer. Culture ( $30 \mathrm{~g}, \mathrm{CHN}-11)$ was added to the milk to achieve $20 \mathrm{~g}$ culture per liter, and stirred continuously for $5 \pm 0.5 \mathrm{~min}$ until the culture was thoroughly incorporated into the milk. Next, $100 \mathrm{~mL}$ of the milk/culture mix was distributed into 12 mason jars ( $250 \mathrm{~mL}$ each) and was immediately capped and placed in an incubator preheated to $42{ }^{\circ} \mathrm{C}$ for $12 \mathrm{~h}$ to set the yogurt and achieve a titratable acidity between 0.3 and $0.5 \%$ and a $\mathrm{pH}<5$. After incubation, the yogurt was equally distributed into two $1000 \mathrm{~mL}$ beakers to have $600 \mathrm{~mL}$ of yogurt in each beaker. The beakers were labeled "control" (unfortified) and "fortified". To prepare chhash, the yogurt was diluted with double deionized water (DDI) by adding $210 \mathrm{~mL}$ DDI to $600 \mathrm{~mL}$ yogurt and thoroughly mixed for $5 \mathrm{~min}$ using a handheld mixer. To prepare fortified chhash at $32 \mathrm{mg}$ fortificant per $250 \mathrm{~mL}, 104 \mathrm{mg}$ of premix was thoroughly mixed ( $2 \mathrm{~min}$ ) with a $100 \mathrm{~mL}$ aliquot of chhash from the "fortified" beaker followed by mixing it back into the large beaker $(810 \mathrm{~mL})$ and sonicating in a water bath for 2 minutes. Finally, control and fortified chhash $(135 \mathrm{~mL})$ was transferred to six mason jars and capped. Two jars from each treatment were placed in the refrigerator $\left(4 \pm 0.5^{\circ} \mathrm{C}\right)$, two were placed in a dark box (to prevent vitamin degradation due to light exposure) at room temperature $\left(23 \pm 2{ }^{\circ} \mathrm{C}\right)$, and two were placed in an incubator $\left(40 \pm 2{ }^{\circ} \mathrm{C}\right)$ for each time point. The protocol was repeated to prepare samples for each time point (day 1, 2,3 and 6).

\section{5. $p H$ and Titratable Acidity}

The $\mathrm{pH}$ and titratable acidity were measured using Method number 981.12 and Method 947.05 of the Association of Analytical Communities (AOAC), respectively [12]. Briefly, the $\mathrm{pH}$ meter was calibrated, the probe was placed in the middle of the sample and the reading was recorded after reaching stabilization. The titratable acidity was analyzed by filling a $100 \mathrm{~mL}$ burette with $0.1 \mathrm{~N} \mathrm{NaOH}$. Then, $10 \mathrm{~g}$ of chhash, $30 \mathrm{~mL}$ deionized distilled water, and $1 \mathrm{~mL}$ phenolphthalein were mixed in a $250 \mathrm{~mL}$ Erlenmeyer flask. The mixture was swirled underneath a constant stream of $\mathrm{NaOH}$ until a pink endpoint was held for at least 10 seconds. Titratable acidity (expressed as \% lactic acid) was calculated using Equation (1),

$$
\text { Titratable acidity }(\text { as } \% \text { lactic acid })=\frac{\mathrm{V} \times \mathrm{N} \times \mathrm{W} \times 100}{\mathrm{MW} \times 1000}
$$

where $\mathrm{V}$ is the volume in $\mathrm{mL}$ of $0.1 \mathrm{~N} \mathrm{NaOH}$ used in titration; $\mathrm{N}$ is the normality of $\mathrm{NaOH}$ used in titration; MW is the molecular weight of lactic acid ( $90 \mathrm{~g} / \mathrm{mol})$; and $\mathrm{W}$ is the weight of the sample.

\subsection{Color}

The color of the chhash samples was measured using the HunterLab (Labscan XE, Hunter Associates Laboratory, Inc., Reston, VA, USA). Briefly, all samples were brought to room temperature $\left(25 \pm 2{ }^{\circ} \mathrm{C}\right)$ before testing. Chhash sample $(15 \mathrm{~mL})$ was poured into a Petri dish $(100 \mathrm{~mm} \times 15 \mathrm{~mm})$ and measured in terms of $\mathrm{L}^{*}$ (lightness) and $\mathrm{a}^{*} \mathrm{~b}^{*}$ (chroma). Calibration using standard reference plates prior to sample analysis was conducted. The absolute measure of change in color was calculated as the $\Delta \mathrm{E}-76$ value using Equation (2),

$$
\Delta \mathrm{E} *=\sqrt{\left(\mathrm{L}_{\mathrm{f} *}-\mathrm{L}_{\mathrm{c} *}\right)^{2}+\left(\mathrm{A}_{\mathrm{f} *}-\mathrm{A}_{\mathrm{c} *}\right)^{2}+\left(\mathrm{B}_{\mathrm{f} *}-\mathrm{B}_{\mathrm{c} *}\right)^{2}}
$$


where, $\mathrm{L}_{\mathrm{f}^{*}}, \mathrm{~A}_{\mathrm{f}^{*}}$ and $\mathrm{B}_{\mathrm{f}^{*}}$ are the $\mathrm{L}^{*}, \mathrm{a}^{*}$, and $\mathrm{b}^{*}$ values of fortified samples, and $\mathrm{L}_{\mathrm{c}^{*}}, \mathrm{~A}_{\mathrm{c}^{*}}$ and $\mathrm{B}_{\mathrm{c}^{*}}$ are $\mathrm{L}^{*}, \mathrm{a}^{*}$, and $b^{*}$ values of the control sample. The equation integrates the values for $L^{*}, a^{*}$ and $b^{*}$ into a single formula to determine total perceivable color difference based on reference [13] as shown in Table 2.

Table 2. Correlation between $\Delta \mathrm{E}-76$ values and human eye perception.

\begin{tabular}{cc}
\hline$\Delta \mathbf{E}^{*}$ & Human Eye Perception \\
\hline$\leq 1.0$ & Not perceptible by human eyes \\
$1-2$ & Perceptible through close observation \\
$2-10$ & Perceptible at a glance \\
$11-49$ & Colors are more similar than opposite \\
100 & Colors are the exact opposite \\
\hline
\end{tabular}

\subsection{Viscosity}

The viscosity of chhash samples was measured using a Brookfield viscometer (Model DV-II Pro, Brookfield Engineering Laboratories, Middleboro, MA, USA) with an RV2 spindle. A chhash sample $(130 \mathrm{~mL})$ at a temperature $5 \pm 1{ }^{\circ} \mathrm{C}$ was placed in $250 \mathrm{~mL}$ beaker and was analyzed at $60 \mathrm{rpm}$ after $30 \mathrm{~s}$ of shear [14]. The samples were analyzed on day 0 and day 6 .

\subsection{Sensory Test}

Research protocols used in this study were similar to those recently reported by Gaur et al. 2018 and were approved by the Institutional Review Board at the University of Illinois, Urbana-Champaign [15]. The study was conducted in collaboration with the Mansinhbhai Institute of Dairy and Food Technology (MIDFT), Mehsana, India. Untrained individuals, 58 college students (18-24 years) and 25 mothers (18-45 years) with young children, all of whom were otherwise healthy (no diarrhea, cold, or fever), were randomly recruited from MIDFT and within a $20 \mathrm{~km}$ radius from MIDFT, respectively. The number of assessors was calculated using a sensitivity test at $\alpha$-risk (strength of evidence that the difference was apparent) of $0.05, \beta$-risk (strength of evidence that the difference was not apparent) of 0.05 and $p_{\mathrm{d}}$ (maximum allowable proportion of distinguishers) of $50 \%$ to keep the amount of tasting within reasonable limits. Written consents were obtained from the participants on the day of the tests. Mothers with young children were enrolled in this study as women and children ( $>5$ years of age) population are most vulnerable to micronutrient deficiencies and Indian mothers normally seek and provide food and care for young children, who are also at homes. Students from MIDFT are considered a convenient sample as the intention of the test was to identify by sensory evaluation the presence of micronutrients in the fortified chhash samples. Thus, the purpose of this test was to assess whether subjects could detect any difference between the control and fortified chhash using a triangle sensory test [16]. Chhash samples were prepared one day in advance in a food grade lab at MIDFT and were transferred to the test site under refrigerated conditions $\left(4 \pm 2{ }^{\circ} \mathrm{C}\right)$. Panelists were served one tray at a time with three samples of chhash samples $(2 \pm 0.5 \mathrm{~g})$ placed in random order and identified only by three-digit codes. One of the samples contained fortified chhash and the other two samples contained the control or vice versa. When presented with the samples, the panelists were requested to look at the samples and select the odd sample. Next, the tray was replaced with another set of three coded samples and the panelists were requested to smell and select the odd one. Finally, the tray was replaced one more time and the panelists were asked to rinse their palate with water $\left(25 \pm 2{ }^{\circ} \mathrm{C}\right)$ and taste the sample and select the odd one. The samples were maintained at $4 \pm 2{ }^{\circ} \mathrm{C}$ and all tests were performed in well-lit and ventilated rooms. All testing sessions were scheduled between 11:00 AM and 1:00 PM. The subjects who were able to identify the different sample (correct) were given a score 
of 1 whereas the others (incorrect) were given a score of 0 . The total number of correct responses was then compared with the critical number at $\alpha=0.05$, calculated using equation (3),

$$
\mathrm{Z}_{\text {critical }}=\frac{\mathrm{k}-\frac{1}{3} \times n}{\sqrt{\frac{2}{9} \times n}}
$$

where $\mathrm{k}$ is the minimum number of correct responses to reject the assumption of "no difference", $n$ is the total number of participants [16].

\subsection{Statistics}

Statistical analyses were performed using SAS (SAS Institute, Cary, NC, USA). All experiments were conducted in duplicates, and the results are reported as mean \pm SD. For all analyses, determinations were made in triplicate as independent experiments. Data were analyzed by a three-way analysis of variance (ANOVA) (treatment $\times$ storage temperature $\times$ storage time) for titratable acidity and $\mathrm{pH}$ outcomes, two-way ANOVA (treatment $\times$ storage temperature) for viscosity outcomes. The lack of fit test $F$-values were used to reflect if the models were significant and coefficient of variance less than $10 \%$ was used to establish that the experiments were conducted with reasonable accuracy and suggesting that the models can be reproducible. The Tukey's Honest Significant Difference test was used to compare means. Statistical significance was established at an alpha of 0.05 .

\section{Results}

\section{1. $\mathrm{pH}$ and Titratable Acidity}

Micronutrient fortification had no effect on the titratable acidity and $\mathrm{pH}$ at any given temperature and time, except for day 3 where the titratable acidity of control and fortified samples was slightly different ( $p>0.05$; Figure 1, bottom graph). Both storage temperature and time point (day) and their respective interactions were significant $(p<0.05)$ for both titratable acidity and $\mathrm{pH}$. The titratable acidity for both fortified and control samples did not change over time for samples stored at $4{ }^{\circ} \mathrm{C}$. Control and fortified samples showed high titratable acidity $(p<0.05)$ after several days of storage at 23 and $40{ }^{\circ} \mathrm{C}$. Similarly, the $\mathrm{pH}$ of samples did not change after storage at $4{ }^{\circ} \mathrm{C}$. Samples showed a reduced $\mathrm{pH}$ after several days of storage at 23 and $40{ }^{\circ} \mathrm{C}$ (Figure 1, top graph). 


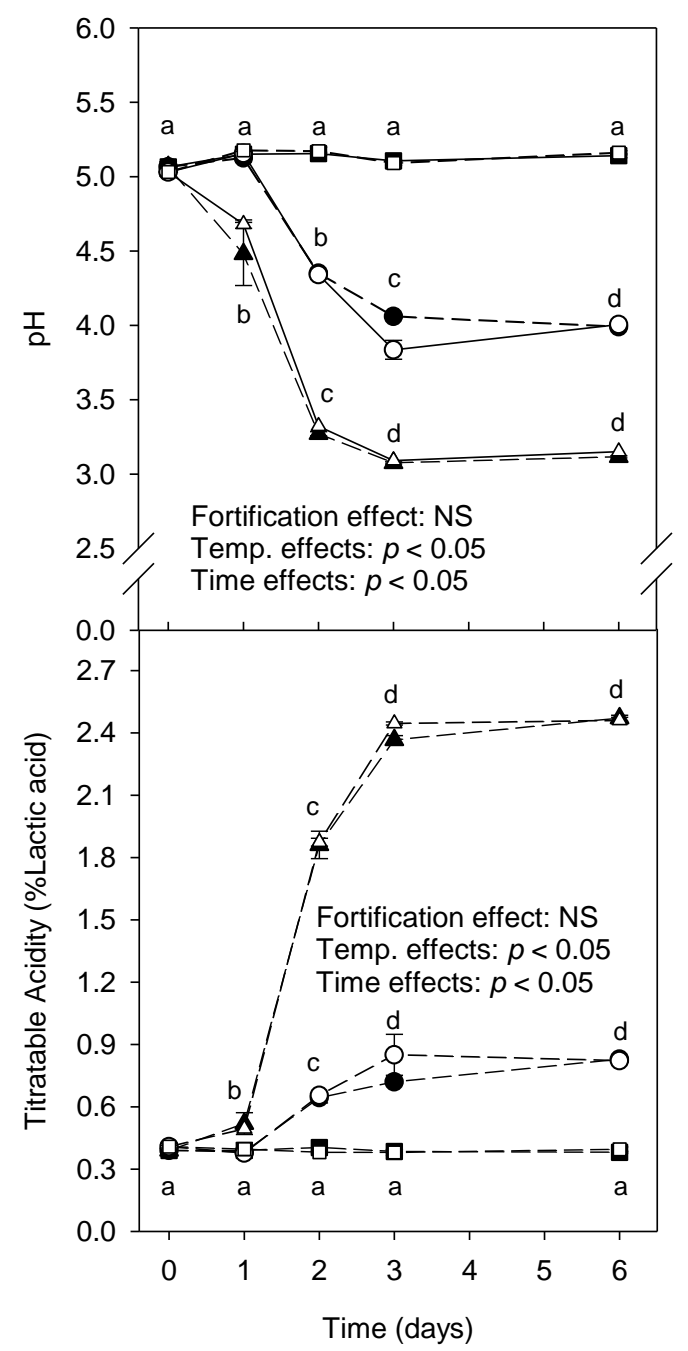

Figure 1. Changes in $\mathrm{pH}$ and titratable acidity of control and fortified chhash samples over 6 days stored under refrigeration (squares; $4 \pm 1^{\circ} \mathrm{C}$ ), room temperature (circles; $23 \pm 2{ }^{\circ} \mathrm{C}$ ), and in an incubator (triangles; $40 \pm 2{ }^{\circ} \mathrm{C}$ ). Data points represent means $\pm \mathrm{SD}$. Different superscripts $(\mathrm{a}, \mathrm{b}, \mathrm{c}, \mathrm{d})$ indicate significant differences across temperature $\mathrm{x}$ time interactions (repeated measures ANOVA; $p<0.05$ ).

\subsection{Color}

Fortified samples had higher $\mathrm{b}$ values for color $(p<0.05)$ compared to the control samples across all time points and temperatures, suggesting an increased yellowness due to fortification. $L^{*}$ and $\mathrm{a}^{*}$ color values were not different across treatments, times, and temperatures. Based on Table 2 (i.e., $\Delta \mathrm{E}-76$ ), fortified samples stored at 4 and $40^{\circ} \mathrm{C}$ can be perceived at a glance by the human eye (Figure 2). 


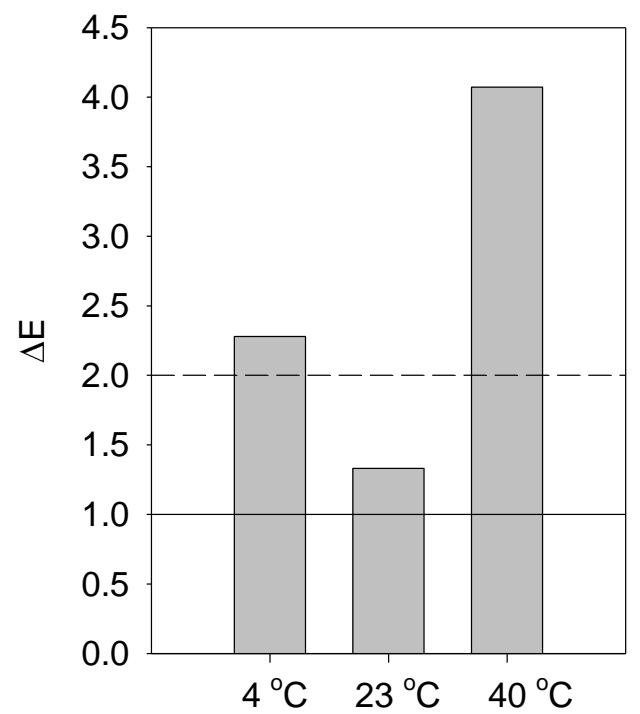

Figure 2. Perception of color difference between fortified and control samples $(\Delta \mathrm{E})$ stored under refrigeration $\left(4 \pm 1^{\circ} \mathrm{C}\right)$, at room temperature $\left(23 \pm 2{ }^{\circ} \mathrm{C}\right)$, or in an incubator $\left(40 \pm 2{ }^{\circ} \mathrm{C}\right)$. The dashed and solid lines indicate perceptible at a glance (above dashed line) and not perceptible by human eyes (below the solid line). Between the dashed and solid lines indicate perceptible through close observation (See Table 2).

\subsection{Viscosity}

Micronutrient fortification had no effect on the viscosity of samples stored at all temperatures on day 6 (Figure 3). After 6 days of storage at $40{ }^{\circ} \mathrm{C}$, samples showed increased viscosity $(p<0.05$, range 235.3 to $228.3 \mathrm{cP})$. Viscosity did not change among samples stored at 4 and $23^{\circ} \mathrm{C}(p>0.05$, range 81.6 to $105.1 \mathrm{cP})$.

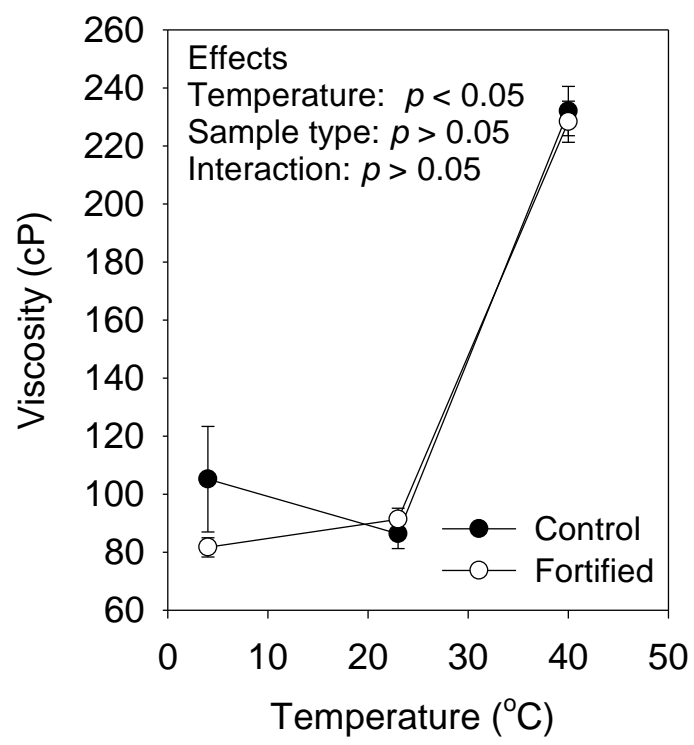

Figure 3. Apparent viscosity (Brookfield viscometer) of control and fortified chhash samples measured after six days of storage under refrigeration $\left(4 \pm 1{ }^{\circ} \mathrm{C}\right)$, at room temperature $\left(23 \pm 2{ }^{\circ} \mathrm{C}\right)$, an in an incubator $\left(40 \pm 2{ }^{\circ} \mathrm{C}\right)$. Data points represent means $\pm \mathrm{SD}$. $p$-values shown correspond to statistical analyses using two-way ANOVA for treatment and temperature factors, and their interactions. 


\subsection{Sensory Test}

Figure 4 shows that both student and mothers with young children were not able to discriminate between the control and fortified chhash samples, given the sensitivity levels selected for the test $\left(p_{\mathrm{d}}=50 \%, \alpha=0.05, \beta=0.05\right)$.

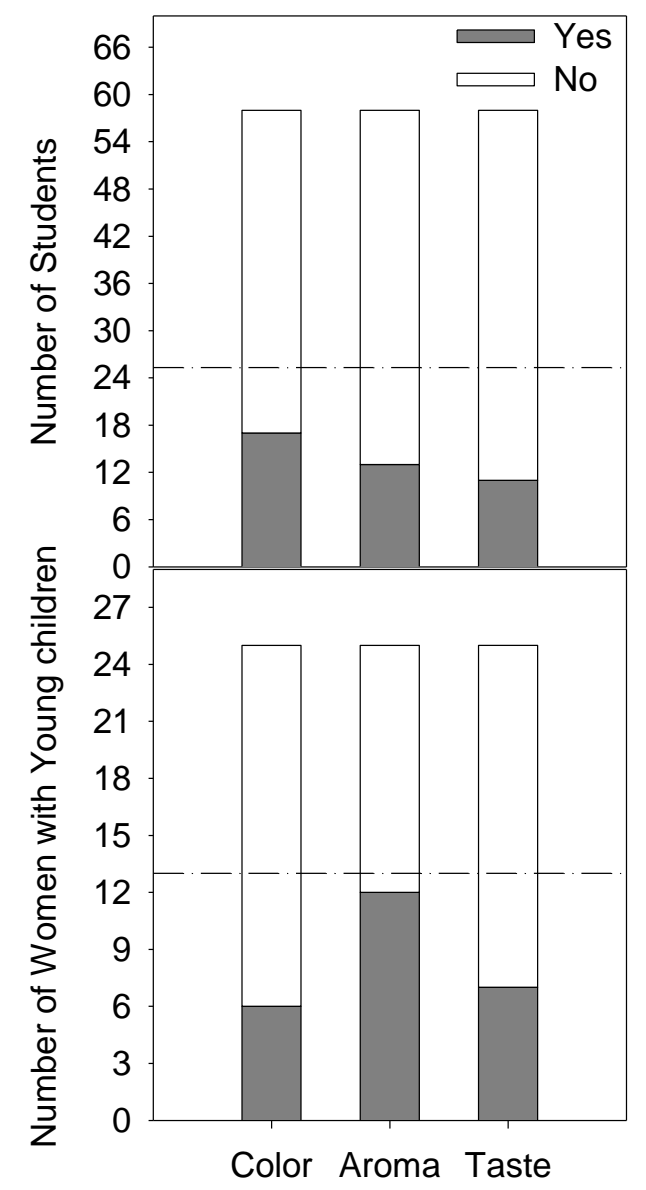

Figure 4. Sensory evaluation showing no differences $\left(p<0.05\right.$; sensitivity levels: $p_{\mathrm{d}}=50 \%, \alpha=0.05$, $\beta=0.05$ ) between control and fortified samples in terms of color, aroma, and taste as evaluated by students $(n=58)$ and mothers with young children $(n=25)$ in Mehsana, India.

\section{Discussion}

Fortification is a nutrition specific strategy which has been implemented worldwide to address micronutrient deficiencies [17]. Extensive evidence supports the effectiveness of the use of staples such as salt, cereal flours, milk, and sugar for the successful delivery of iodine, iron, folic acid, and vitamin A to a diverse population [18-21]. Despite its long-standing application, more than 2 billion people continue to suffer from hidden hunger [22]. One of the many factors that hinder fortification success is the technical feasibility of the fortificant and the chosen product, which encompasses the consumption pattern, the level of fortification, the stability of premixes, the interactions among nutrients, and the physical-chemical changes that could affect final product's acceptability and use [23]. In this study, the authors sought to address some of these limitations by proposing the fortification of chhash, a traditional fermented dairy product widely consumed in India. This study was performed in the light of a newly passed Food Safety and Standards Regulations (2017) [7] on the fortification of dairy products with the specific objective of exploring the effect of a micronutrient premix on the physico-chemical properties of chhash.

The manufacture of dairy fermented products includes a variety processing and ingredient technologies, which results in their distinctive textures, colors, mouthfeels, and sour flavors [24]. 
Despite its importance, the addition of micronutrients into foods cannot succeed at the expense of modifications in flavor, to standards of identity (e.g., $\mathrm{pH}, \mathrm{TA}$ ), or any other characteristics that make products like chhash a unique drink. The addition of the micronutrient premix to chhash did not result in changes in its physical-chemical characteristics, even at temperatures not recommended for storage. Previous, related studies on the fortification of dairy products showed no effect on titratable acidity and $\mathrm{pH}$ [25-28]. Fortification of yogurt with Vitamin A and $\mathrm{C}$ did not change $\mathrm{pH}$, titratable acidity, or sensory characteristics of yogurt samples stored at $3{ }^{\circ} \mathrm{C}$ for 6 weeks [25]. The addition of microor nanosized iron, zinc, and calcium into yogurt did not affect $\mathrm{pH}$ or titratable acidity after 28 days at $4{ }^{\circ} \mathrm{C}$ [28]. Vitamin $\mathrm{D}$ has been reported to be stable in yogurt during processing and storage [29]. In agreement with those studies, the present results indicate that micronutrient fortification had no significant effect on titratable acidity and $\mathrm{pH}$ at any given temperature. As expected, storage temperature and time increased titratable acidity and reduced $\mathrm{pH}$. This has been shown by other groups, in which the exposure of yogurt to higher temperature over several hours or days allows for further microbial activity beyond the initial sample preparation time of $12 \mathrm{~h}$ [30-32]. Previous studies report similar findings of yogurt increasing titratable acidity and decreasing $\mathrm{pH}$ with storage at room temperature or above. Because of these changes in product quality, it is important for the consumer to properly refrigerates these products. Similarly, there was no change in apparent viscosity after micronutrient fortification. However, the samples stored at $40{ }^{\circ} \mathrm{C}$ increased their apparent viscosity. This is due to increased microbial activity, which continued the fermentation process and resulted in protein denaturation and gelation [33].

Chhash presents a white, milky color. Addition of micronutrients can unduly influence food's color. The addition of the micronutrient premix influenced the color toward light yellow. One study found that fortification of chocolate milk with sodium ferric pyrophosphate did not change color as determined with a color difference meter initially or after 14 days holding at $4{ }^{\circ} \mathrm{C}$ [10]. This may be due, however, to the natural brown color of chocolate milk, which could obscure a change in yellowness. Although the fortification caused a significant change in chhash yellowness, the sensory study results indicate that a change in color is not perceivable to the target consumer population. Moreover, in several regions of India, fermented products are mixed with spices [9], which could potentially mask any sensory modification due to micronutrient fortification.

The present findings indicating no sensory difference between fortified and unfortified chhash are in agreement with a previous study, in which both a trained and a consumer panel detected no significant difference in terms of appearance, mouthfeel, flavor, or overall quality on a nine-point hedonic scale when evaluating iron fortified yogurt [34]. In another study, chocolate milk fortified with sodium ferric pyrophosphate produced little or no off-flavors initially or after holding at $4{ }^{\circ} \mathrm{C}$ for 14 days [10]. As the present work was conducted using a mixed consumer panel (i.e., mothers with young children and young adults of both sexes), it can be speculated that other consumers would accept both products equally, however, this requires further evaluation.

A limitation of this study is that the contents of the micronutrients added were not measured after exposure to time and temperature conditions. Nonetheless, prior evidence demonstrates and recommends the storage of fermented products under refrigeration to maintain their nutritional content (mainly of vitamins) and physico-chemical attributes before their consumption. In those studies, some micronutrients (i.e., vitamins C, A and D) losses occurred due to exposure to broad wavelength light, temperature and time $[25,35,36]$.

\section{Conclusions}

The addition of micronutrients to chhash would bear no technical and sensory barriers to its current format of consumption. Furthermore, the results of this study indicate that this fortified dairy product would be feasible and acceptable to enter the market under the current Food Safety and Standards Regulations (Fortification of Foods). Studies evaluating processing feasibility of the fortification of chhash at a pilot or large-scale are needed. 
Author Contributions: Conceptualization, J.E.A. and S.G.; Methodology, S.G. and A.W.W.; Software, S.G.; Formal Analysis, S.G. and A.W.W.; Resources, J.E.A.; Writing-Original Draft Preparation, S.G.; Writing-Review \& Editing, S.G., A.W.W., J.E.A.; Visualization, J.E.A.; Project Administration, J.E.A.; Funding Acquisition, J.E.A.

Funding: This work was partially supported by USDA-Hatch ILLU-698-904, The College of ACES Office of International Programs, and the Indian Council of Agricultural Research International Fellowship, India.

Acknowledgments: The authors are grateful to study volunteers for their participation.

Conflicts of Interest: The authors declare no conflict of interest.

\section{References}

1. Naghavi, M.; Wang, H.; Lozano, R.; Davis, A.; Liang, X.; Zhou, M. GBD 2013 Mortality and Causes of Death Collaborators Global, regional and national levels of age-specific mortality and 240 causes of death, 1990-2013: A systematic analysis for the Global Burden of Disease Study 2013. Lancet 2015, 385, 117-171.

2. Indian National Science Academy Micronutrient Security for India-Priorities for Research and Action; Indian National Science Academy: New Delhi, India, 2011.

3. Kotecha, P. Micronutrient malnutrition in India: Let us say "no" to it now. Indian J. Community Med. 2008, 33, 9-10. [CrossRef] [PubMed]

4. $\quad$ Black, R.E.; Allen, L.H.; Bhutta, Z.A.; Caulfield, L.E.; de Onis, M.; Ezzati, M.; Mathers, C.; Rivera, J. Maternal and child undernutrition: Global and regional exposures and health consequences. Lancet 2008, 371, 243-260. [CrossRef]

5. Itkonen, S.T.; Erkkola, M.; Lamberg-Allardt, C.J.E. Vitamin D fortification of fluid milk products and their contribution to vitamin D intake and vitamin D status in observational studies-A review. Nutrients 2018, 10, 1054. [CrossRef] [PubMed]

6. Yeh, E.B.; Barbano, D.M.; Drake, M.A. Vitamin Fortification of Fluid Milk. J. Food Sci. 2017, 82, 856-864. [CrossRef]

7. Food Safety and Standards Authority of India. Food Safety and Standards (Fortification of Foods) Regulations; Food Safety and Standards Authority of India: New Delhi, India, 2018; p. 13.

8. Prajapati, J.B.; Nair, B.M. The History of Fermented Foods. In Handbook of Fermented Functional Foods; Farnworth, E.R., Ed.; CRC Press: Boca Raton, FL, USA, 2003; pp. 2-23.

9. Satish Kumar, R.; Kanmani, P.; Yuvaraj, N.; Paari, K.A.; Pattukumar, V.; Arul, V. Traditional Indian fermented foods: A rich source of lactic acid bacteria. Int. J. Food Sci. Nutr. 2013, 64, 415-428. [CrossRef]

10. Douglas, F.W.; Rainey, N.H.; Wong, N.P.; Edmondson, L.F.; LaCroix, D.E. Color, Flavor, and Iron Bioavailability in Iron-Fortified Chocolate Milk. J. Dairy Sci. 1981, 64, 1785-1793. [CrossRef]

11. Routray, W.; Mishra, H.N. Scientific and Technical Aspects of Yogurt Aroma and Taste: A Review. Compr. Rev. Food Sci. Food Saf. 2011, 10, 208-220. [CrossRef]

12. Association of Official Analytical Chemists (AOAC). Official Methods of Analysis of AOAC International, 19th ed.; AOAC International: Gaithersburg, MD, USA, 2012.

13. Brainard, D.H. Color Appearance and Color Difference Specification. In The Science of Color, 2nd ed.; Elsevier: Amsterdam, The Netherlands, 2003.

14. Gursoy, O.; Yilmaz, Y.; Gokce, O.; Ertan, K. Effect of ultrasound power on physicochemical and rheological properties of yoghurt drink produced with thermosonicated milk. Emir. J. Food Agric. 2016, 28, 235-241. [CrossRef]

15. Gaur, S.; Lopez, E.C.; Ojha, A.; Andrade, J.E. Functionalization of Lipid-Based Nutrient Supplement with $\beta$-Cyclodextrin Inclusions of Oregano Essential Oil. J. Food Sci. 2018, 83, 1748-1756. [CrossRef]

16. Meilgaard, M.C.; Carr, B.T.; Civille, G.V. Sensory Evaluation Techniques; CRC Press, Inc.: Boca Raton, FL, USA, 1999.

17. Das, J.K.; Salam, R.A.; Kumar, R.; Bhutta, Z.A. Micronutrient fortification of food and its impact on woman and child health: A systematic review. Syst. Rev. 2013, 2, 67. [CrossRef]

18. Pachón, H.; Spohrer, R.; Mei, Z.; Serdula, M.K. Evidence of the effectiveness of flour fortification programs on iron status and anemia: A systematic review. Nutr. Rev. 2015, 73, 780-795. [CrossRef]

19. Blencowe, H.; Cousens, S.; Modell, B.; Lawn, J. Folic acid to reduce neonatal mortality from neural tube disorders. Int. J. Epidemiol. 2010, 39, i110-i121. [CrossRef] 
20. Dary, O.; Mora, J.O. Food Fortification to Reduce Vitamin A Deficiency: International Vitamin A Consultative Group Recommendations. J. Nutr. 2002, 132, 2927S-2933S. [CrossRef] [PubMed]

21. Phillips, M.; Sanghvi, T.; Suárez, R.; McKigney, J.; Fiedler, J. The costs and effectiveness of three vitamin A interventions in Guatemala. Soc. Sci. Med. 1996, 42, 1661-1668. [CrossRef]

22. Food and Agriculture Organization (FAO); International Fund for Agricultural Development (IFAD); United Nations International Children'sEmergency Fund (UNICEF); World Food Programme (WFP); World Health Organization (WHO). The State of Food Security and Nutrition in the World. Building Climate Resilience for Food Security and Nutrition; FAO: Rome, Italy, 2018.

23. Allen, L.; de Benoist, B.; Dary, O.; Hurrell, R. Guidelines on Food Fortification with Micronutrients; WHO: Geneva, Switzerland, 2006.

24. Sfakianakis, P.; Tzia, C. Conventional and Innovative Processing of Milk for Yogurt Manufacture; Development of Texture and Flavor: A Review. Foods 2014, 3, 176-193. [CrossRef] [PubMed]

25. Ilic, D.B.; Ashoor, S.H. Stability of vitamins A and C in fortified yogurt. J. Dairy Sci. 1988, 71, 1492-1498. [CrossRef]

26. Drago, S.R.; Valencia, M.E. Effect of fermentation on iron, zinc, and calcium availability from iron-fortified dairy products. J. Food Sci. 2002, 67, 3130-3134. [CrossRef]

27. El-Kholy, A.M.; Osman, M.; Gouda, A.; Ghareeb, W.A. Fortification of Yoghurt with Iron. J. Dairy Food Sci. 2011, 6, 159-165.

28. Santillán-Urquiza, E.; Méndez-Rojas, M.Á.; Vélez-Ruiz, J.F. Fortification of yogurt with nano and micro sized calcium, iron and zinc, effect on the physicochemical and rheological properties. LWT Food Sci. Technol. 2017, 80, 462-469. [CrossRef]

29. Kazmi, S.A.; Vieth, R.; Rousseau, D. Vitamin D3 fortification and quantification in processed dairy products. Int. Dairy J. 2007, 17, 753-759. [CrossRef]

30. Al-Kadamany, E.; Khattar, M.; Haddad, T.; Toufeili, I. Estimation of shelf-life of concentrated yogurt by monitoring selected microbiological and physicochemical changes during storage. LWT Food Sci. Technol. 2003, 36, 407-414. [CrossRef]

31. Al-Kadamany, E.; Toufeili, I.; Khattar, M.; Abou-Jawdeh, Y.; Harakeh, S.; Haddad, T. Determination of Shelf Life of Concentrated Yogurt (Labneh) Produced by In-Bag Straining of Set Yogurt using Hazard Analysis. J. Dairy Sci. 2002, 85, 1023-1030. [CrossRef]

32. Beal, C.; Skokanova, J.; Latrille, E.; Martin, N.; Corrieu, G. Combined Effects of Culture Conditions and Storage Time on Acidification and Viscosity of Stirred Yogurt. J. Dairy Sci. 1999, 82, 673-681. [CrossRef]

33. Lin, Y.; Kelly, A.L.; O'Mahony, J.A.; Guinee, T.P. Fortification of milk protein content with different dairy protein powders alters its compositional, rennet gelation, heat stability and ethanol stability characteristics. Int. Dairy J. 2016, 61, 220-227. [CrossRef]

34. Hekmat, S.; McMahon, D.J. Manufacture and Quality of Iron-Fortified Yogurt. J. Dairy Sci. 1997, 80, 3114-3122. [CrossRef]

35. Jafari, T.; Askari, G.; Mirlohi, M.; Javanmard, S.; Faghihimani, E.; Fallah, A. Stability of Vitamin D 3 in fortified yoghurt and yoghurt drink (Doogh). Adv. Biomed. Res. 2016, 5, 52.

36. De Brabandere, A.G.; De Baerdemaeker, J.G. Effects of process conditions on the $\mathrm{pH}$ development during yogurt fermentation. J. Food Eng. 1999, 41, 221-227. [CrossRef]

(C) 2018 by the authors. Licensee MDPI, Basel, Switzerland. This article is an open access article distributed under the terms and conditions of the Creative Commons Attribution (CC BY) license (http:/ / creativecommons.org/licenses/by/4.0/). 